\title{
P02.76. Impedance plethysmographic (IPG) pulse signal analysis based personalized diagnostics \& treatment simulating Ayurvedic pulse examination
}

\author{
M Dhurandhar \\ From International Research Congress on Integrative Medicine and Health 2012 \\ Portland, Oregon, USA. 15-18 May 2012
}

\section{Purpose}

Ayurveda advocates a holistic, individualized approach for disease diagnostics/treatment. Taking cognizance of physiological variabilities, Ayurveda devised a subjective method of pulse examination for health index assessment. As per Ayurveda, biological humors 'TriDosha' are fundamental psychosomatic principles responsible for health/ diseases (Vata: Body Movements; Pitta: Heat, Metabolism; Kapha: Body Resistance). Doshas in homeostasis lead to health and imbalance lead to disease. Ayurvedic Pulse characteristics like Strength/Rate/Rhythm/Movement contribute to assessment of prodromal symptoms predicting diseases, diagnosing metabolic status, identifying causative agents, prognosis and lifespan. Integrative medical informatics tools are developed for IPG-based pulse signal analysis harnessing Ayurveda's clinical phenotyping principles and mathematical modeling with information technology for clinical assessment of pulse qualities.

\section{Methods}

Pulse examination by Ayurveda doctor and pulse signal captured with IPG-based medical instrument. Correlation found between Power Spectral Density (PSD) of Heart Rate Variability (HRV) and dominant Dosha; pulse morphology patterns and parameters like strength, rate, rhythm, movement. This was done in a population of 1000 healthy patients.

\section{Results}

Frequency bands of PSD of HRV showed signal intensity corresponding to Dosha levels (LF:Pitta; MF:Kapha; HF:
Vata). Dosha corresponding to the band with maximum signal intensity found dominant ( $>85 \%$ accuracy). Ratios derived from morphology patterns' deflection points yielded characteristics like strength with high $(\geq 91 \%)$ accuracy.

\section{Conclusion}

Few attempts are made to objectively evaluate autonomous nervous system functioning for patient benefit. With today's high stress-induced lifestyle, a major technological shift is emerging towards Integrative Medicine. Pharmacogenomics being in use to a limited degree, such multidisciplinary research can lead to evidence-based results, impacting optimal promotive/preventive/curative healthcare management by early changes in lifestyle, avoiding or lessening severity of diseases, and decreasing cost and risk of clinical trials by targeting persons capable of responding to a drug. Decreases in adverse drug reactions, failed drug trials, length of medication time, number. of medications taken for finding an effective therapy, and early detection will promote decrease in healthcare costs.

Published: 12 June 2012

doi:10.1186/1472-6882-12-S1-P132

Cite this article as: Dhurandhar: P02.76. Impedance plethysmographic (IPG) pulse signal analysis based personalized diagnostics \& treatment simulating Ayurvedic pulse examination. BMC Complementary and Alternative Medicine 2012 12(Suppl 1):P132. 